\section{Dibenzo[a,e]pentalenes by ortho C-H Activation}

Gategory

Synthesis of

Materials and

Unnatural Products

\section{Key words}

C-H activation

palladium catalysis

annulation

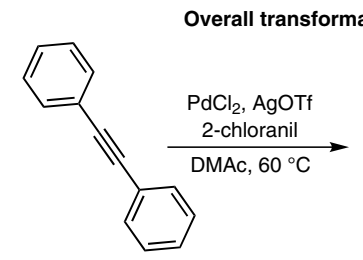

Proposed mechanism:
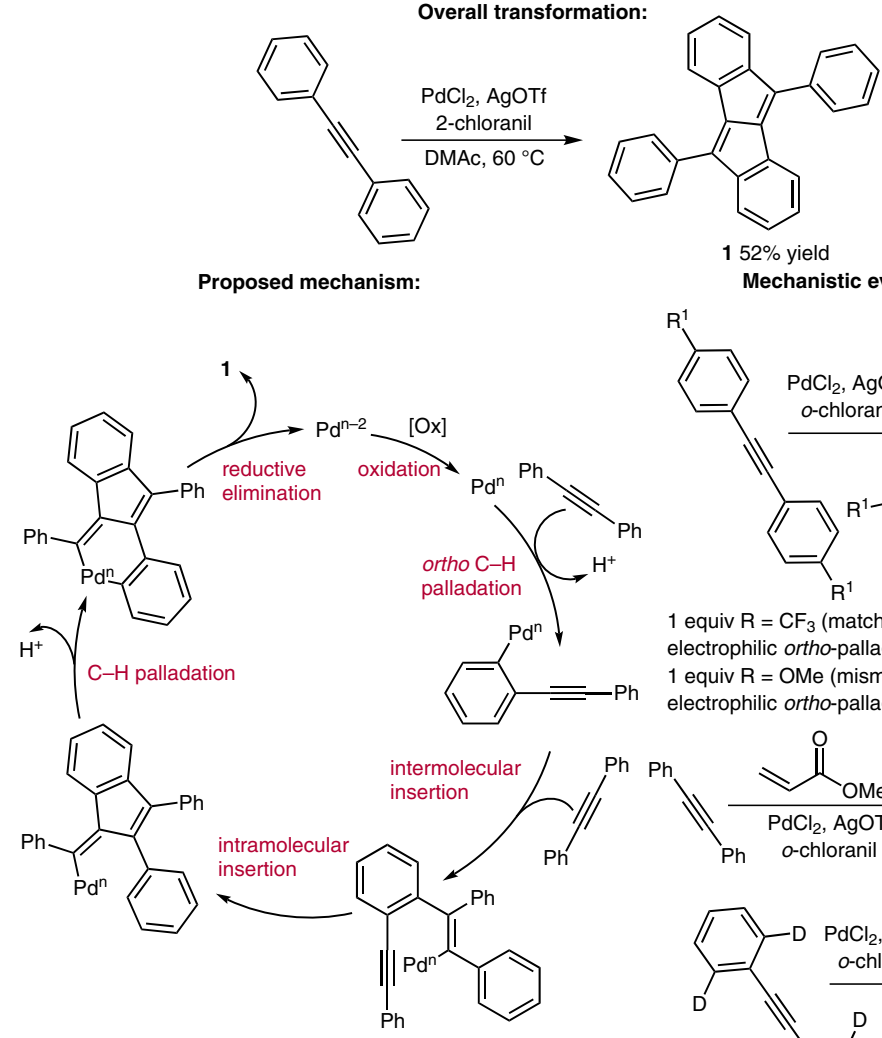

$152 \%$ yield

Mechanistic evidence:

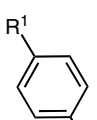

$\mathrm{PdCl}_{2}, \mathrm{AgOTf}$

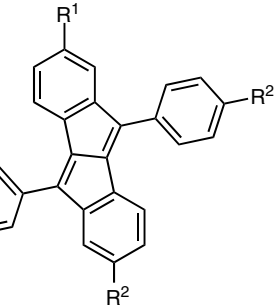

$41 \%, R^{1}, R^{2}=M e$

equiv $\mathrm{R}=\mathrm{CF}_{3}$ (match $\quad 27 \%, \mathrm{R}^{1}=\mathrm{CF}_{3}, \mathrm{R}^{2}=\mathrm{OMe}$

1 equiv $\mathrm{R}=\mathrm{OMe}$ (mismatch for $0 \%, \mathrm{R}^{1}, \mathrm{R}^{2}=\mathrm{OMe}$

electrophilic ortho-palladation)
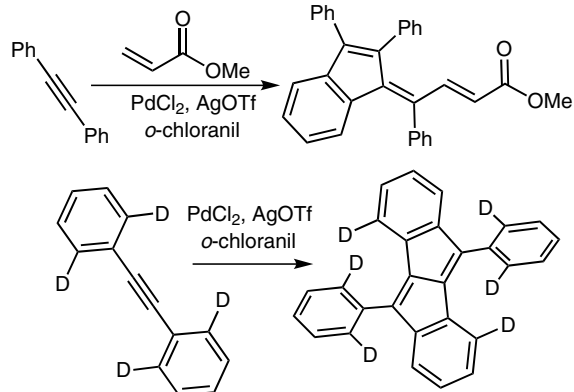

Significance: Itami and co-workers have devised an elegant synthesis of dibenzo[a,e]pentalene (1), a classic $\pi$-conjugated polycyclic hydrocarbon, through the dimerization of aryl acetylenes. Unlike other approaches to $\mathbf{1}$, this method does not require ortho functionalization of the aryl group. Instead, this position is activated through an electrophilic palladation/C-H activation. The ortho selectivity was demonstrated by a deuterium-labeling experiment and an analysis of substituents effects supports the proposed electrophilic palladation mechanism.
Comment: Following the ortho $\mathrm{C}-\mathrm{H}$ activation, a catalytic cycle is proposed involving two insertion steps (intermolecular followed by intramolecular), another $\mathrm{C}-\mathrm{H}$ palladation, and reductive elimination to yield the desired dibenzo[a,e]pentalenes. The cycle is completed by re-oxidation of the palladium. Trapping and cross-dimerization experiments support the hypothesized catalytic cycle. The authors also demonstrate this method is effective with asymmetric aryl acetylenes.

SYNFACTS Contributors: Timothy M. Swager, Ellen M. Sletten 